\title{
Oxidative burst in lipopolysaccharide-activated human alveolar macrophages is inhibited by interleukin-9
}

\author{
C. Pilette*, Y. Ouadrhiri*, J. Van Snick*,\#, J-C. Renauld*,\#, P. Staquet ${ }^{\Uparrow}$, J-P. Vaerman*, Y. Sibille*
}

Oxidative burst in lipopolysaccharide-activated human alveolar macrophages is inhibited by interleukin-9. C. Pilette, Y. Ouadrhiri, J. Van Snick, J-C. Renauld, P. Staquet, J-P. Vaerman, Y. Sibille. C)ERS Journals Ltd 2002.

ABSTRACT: Interleukin (IL)-9 is known to regulate many cell types involved in T-helper type 2 responses classically associated with asthma, including B- and T-lymphocytes, mast cells, eosinophils and epithelial cells. In contrast, target cells mediating the effects of IL-9 in the lower respiratory tract remain to be identified. Therefore, the authors evaluated the activity of IL-9 on human alveolar macrophages (AM) from healthy volunteers.

AM preincubated with IL-9 before lipopolysaccharide (LPS) stimulation exhibited a decreased oxidative burst, as previously shown with IL-4. The inhibitory effect of IL-9 was abolished by anti-hIL-9R $\alpha$ monoclonal antibody, and presence of IL-9 receptors on AM was demonstrated by immunofluorescence. Both IL-4 and IL-9 failed to modulate tumour necrosis factor- $\alpha$, IL-8 and IL-10 release by LPS-stimulated AM. However, several observations suggested that IL-9 and IL-4 act through different mechanisms: 1) interferon- $\gamma$ antagonised the IL-4- but not the IL-9-mediated inhibition of AM oxidative burst; 2) expression of CD14 was downregulated by IL-4 but not by IL-9 and 3 ) production of tumour growth factor- $\beta$ by activated AM was potentiated by IL-9 and not by IL-4, and was required for the IL-9-mediated inhibition of AM oxidative burst.

These observations provide additional information concerning the activity of interleukin-9 in the lung, related to inflammatory or fibrosing lung processes.

Eur Respir J 2002; 20: 1198-1205.
*Experimental Medicine Unit, ${ }^{\#}$ Ludwig Institute for Cancer Research (Brussels branch), Christian de Duve Institute of Cellular Pathology, and "Laboratory of Haematology, Université de Louvain, Brussels, Belgium.

Correspondence: C. Pilette, Unité de Médecine expérimentale, Avenue Hippocrate, 74 BP 7430, B-1200 Bruxelles, Belgique.

Fax: 3227647430

E-mail: charles.pilette@mexp.ucl.ac.be

Keywords: Cytokine, deactivation, interleukin, lipopolysaccharide, lung, macrophage

Received: January 232002

Accepted after revision: June 102002

C. Pilette is currently Aspirant of the Fonds National de la Recherche Scientifique (Belgium, Grant no. 3.4590.99), and Y. Ouadrhiri is supported by the Fondation Lancardis (Switzerland).
Recently, interleukin (IL)-9 has been shown to play an important role in T-helper (Th) type 2 responses, especially in asthma [1]. More specifically, it has been shown that IL-9 potentiates IL-4-induced immunoglobulin (Ig)E production [2], stimulates mast cell proliferation and differentiation [3], activates eosinophil maturation [4] and stimulates mucus production by bronchial epithelial cells [5]. In contrast with IL-4, which has been implicated in cell regulation both in the airways and alveolar spaces, the role of IL-9 in the lower respiratory tract is poorly characterised with regards to potential target cells. Thus, IL-9 can modulate inflammatory and fibrogenic processes occurring in the lower respiratory tract, as shown in mice exposed to silica particles in which IL-9 exerts a protective anti-fibrotic activity [6], but the lung target cells mediating these effects have not been identified.

The current authors recently showed [7] that IL-9 is capable of inhibiting in vitro human blood monocytes activated by lipopolysaccharide (LPS) for the release of oxygen metabolites and tumour necrosis factor (TNF)- $\alpha$, similarly to IL-4. This monocyte deactivation by IL-9 probably accounts for the beneficial activity of IL-9 observed in the model of lethal endotoxaemia [8]. In contrast with other macrophage inhibitory cytokines of the Th2 family, such as IL-4, no effect of IL-9 has so far been reported on lung macrophages. Moreover, it has been reported that differentiated macrophages such as synovial [9] or alveolar macrophages (AM) [10] can exhibit different responses to the same stimulation when compared to blood monocytes.

Therefore, in this study the effects of IL-9 on human AM, which represent the resident phagocytes involved in the first-line defence of the lung [11], were evaluated. More specifically, the oxidative burst and cytokine release, including the release of the profibrotic cytokine tumour growth factor (TGF)- $\beta$, by AM activated by LPS, was studied. These effects were compared with IL-4 and interferon (IFN)- $\gamma$, the prototypic Th2 and Th1 cytokines, respectively, known to modulate the activation state of AM especially with regards to the respiratory burst.

\section{Materials and methods}

Positive recombinant human (rh)IFN- $\gamma$ and TGF- $\beta$ were purchased from Genzyme (Cambridge, UK). RhIL-9 and IL-4 as well as anti-human IL-9R ( $\alpha$ chain) monoclonal antibodies (mAbs) were produced at the Ludwig Institute, Brussels branch, Belgium. 
Anti-IL-9R $\alpha$ clone AH9R2 mAb (mouse IgG2a) was used for indirect immunofluorescence staining, and blocking $\mathrm{mAb}$ against hIL-9R (clone AH9R7, mIgG2b) was used to specifically neutralise IL-9 activity. Human IL-9 was purified as previously described [7]. LPS from Escherichia coli (serotype O55:B5) was purchased from Difco Laboratories (Detroit, MI, USA), and anti-TGF- $\beta 1 \mathrm{mAb}$ (clone TB21, mIgG1) was from Biosource International (Camarillo, CA).

\section{Alveolar macrophage isolation}

Human AM were obtained from seven nonsmoking healthy volunteers by bronchoalveolar lavage (BAL) following a standardised technique [12], after written consent from all volunteers and approval of the BAL procedure by the local ethical committee. BAL cells, represented by $>90 \%$ of macrophages, as assessed on Giemsa-stained cytospins, were allowed to adhere to plastic in complete Roswell Park Memoral Institute medium (cRPMI) (Bio-Whittaker, Walkersville, MD, USA) for $1 \mathrm{~h}$ at $37^{\circ} \mathrm{C}$ to remove nonadherent cells (mainly lymphocytes) by washings with cRPMI. Finally, AM represented $>95 \%$ of total adherent cells at microscopical examination and flow cytometry. Cell viability assessed by the trypan blue exclusion test was at least $90 \%$.

\section{Oxidative burst assay}

AM $\left(0.2 \times 10^{6} \cdot\right.$ well $\left.^{-1}\right)$ were distributed in 96-well flatbottomed plates (Falcon, Becton Dickinson Labware, Bedford, MA, USA), preincubated for $24 \mathrm{~h}$ at $37^{\circ} \mathrm{C}$, 5\% carbon dioxide with rhIL-9 (Ludwig Institute, Brussels, Belguim), rhIL-4 (Ludwig Institute) $\left(20 \mathrm{ng} \cdot \mathrm{mL}^{-1}\right.$ each) or rhIFN- $\gamma$ (Genzyme, Cambrige, UK) $\left(200 \mathrm{U} \cdot \mathrm{mL}^{-1}\right)$ in cRPMI, and stimulated for $20 \mathrm{~h}$ by LPS (from E. coli serotype 055:B5; Difco Laboratories, Detroit, MI, USA) $\left(1 \mu \mathrm{g} \cdot \mathrm{mL}^{-1}\right)$. Intracellular oxidative capacity was assessed as described by BAsS et al. [13], using 2',7'-dichlorofluorescein (DCFH)diacetate (Sigma, St-Louis, MO, USA), which is oxidised into highly fluorescent DCF according to the intracellular amount of hydrogen peroxide $\left(\mathrm{H}_{2} \mathrm{O}_{2}\right)$ produced by the respiratory burst. After lysis with $0.1 \% \mathrm{v} / \mathrm{v}$ Triton X-100 (Sigma) in phosphate-buffered saline (PBS), fluorescence was quantified in a computerised microplate spectrofluorimeter (Packard Instruments, Downers Grove, IL, USA) at $485 \mathrm{~nm}$ excitation/ $530 \mathrm{~nm}$ emission wavelengths and DCF concentrations were deduced from a standard curve of known concentrations of fluorescent DCF (Sigma). Results were corrected for total protein concentration determined in cell lysates by the bicinchoninic acid-based method (Pierce, Rockford, IL, USA) and were expressed as nmoles DCF per mg cell protein.

\section{Cytokine release assay}

AM $\left(0.5 \times 10^{6} \cdot\right.$ well $\left.^{-1}\right)$ were distributed in 24-well plates (Falcon), preincubated for $24 \mathrm{~h}$ with cytokine and further stimulated by LPS as for the oxidative burst assessment. Supernatants were harvested and frozen at $-20^{\circ} \mathrm{C}$ until cytokine titration. Release of TNF- $\alpha$ was quantified by a cytotoxicity bioassay using WEHI 64 cells clone 13, as previously described [14], and rhTNF- $\alpha$ (Boehringer Mannheim Gmbh, Mannheim, Germany) as a standard. IL-8, IL-10 and TGF- $\beta 1$ concentrations were determined by enzymelinked immunosorbent assay. A kit from CLB (Amsterdam, the Netherlands) was used for IL-10 quantitation, following the manufacturer's protocol. A kit from Biosource International (Camarillo, CA, USA) allowed the determination of TGF- $\beta 1$ after the release from its latent complexes by acid treatment of supernatants; TGF- $\beta 1$ was also assessed in crude supernatants. For IL-8, 96-well plates were coated overnight at $4{ }^{\circ} \mathrm{C}$ with $4 \mu \mathrm{g} \cdot \mathrm{mL}^{-1}$ anti-hIL-8 $\mathrm{mAb}$ (clone 6217.11, Sigma) in $100 \mathrm{mM}$ sodium carbonate buffer, $\mathrm{pH}$ 9.6. After washings in PBS containing $0.1 \% \mathrm{v} / \mathrm{v}$ Tween 20 and blocking for $1 \mathrm{~h}$ at $37^{\circ} \mathrm{C}$ with $1 \% \mathrm{w} / \mathrm{v}$ bovine serum albumin in the same buffer, rhIL-8 standards (Biosource International) and supernatants were incubated for $2 \mathrm{~h}$ at $37^{\circ} \mathrm{C}$. Plates were then incubated with $20 \mathrm{ng} \cdot \mathrm{mL}^{-1}$ biotinylated polyclonal anti-hIL-8 Ab (R\&D Systems, Minneapolis, $\mathrm{MN}$, USA) in blocking buffer and, after washings, with horseradish peroidase-conjugated streptavidin (Sigma). The reaction was then developed in $0.03 \% \mathrm{v} / \mathrm{v} \mathrm{H}_{2} \mathrm{O}_{2}$ substrate and $0.42 \mathrm{mM} \mathrm{3,3^{ \prime } , 5 , 5 ^ { \prime } -}$ tetramethylbenzidine as chromogen in $100 \mathrm{mM}$ sodium acetate/citric acid buffer, $\mathrm{pH} 4.9$, stopped with $2 \mathrm{M}$ dihydrogen sulphate, and read in a plate spectrometer at $450 \mathrm{~nm}$. The sensitivity of the TNF- $\alpha$ bioassay was $0.2 \mathrm{pg} \cdot \mathrm{mL}^{-1}$, and that of IL-8, IL-10 and TGF- $\beta 1$ immunoassays $10 \mathrm{pg} \cdot \mathrm{mL}^{-1}, 2 \mathrm{pg} \cdot \mathrm{mL}^{-1}$ and $2 \mathrm{pg} \cdot \mathrm{mL}^{-1}$, respectively. All supernatants were assayed in duplicate.

\section{Immunofluorescence staining}

Surface expression of the IL-9 receptor ( $\alpha$ chain and IL-2R $\gamma$ subunit) on AM was assayed by indirect immunofluorescence. AM $\left(0.2 \times 10^{6} \cdot \mathrm{well}^{-1}\right)$ were incubated at $4^{\circ} \mathrm{C}$ for $1 \mathrm{~h}$ with anti-hIL-9R $\alpha$ mAb (AH9R2 or AH9R7), or with anti-hIL-2R $\gamma$ mAb (clone 38024.11, $\mathrm{mIgG1}$; R\&D Systems), diluted at $10 \mu \mathrm{g} \cdot \mathrm{mL}$ in RPMI containing 3\% foetal bovine serum (FBS). After three washings with RPMI-3\% FBS, AM were incubated at $4^{\circ} \mathrm{C}$ for $1 \mathrm{~h}$ with $10 \mu \mathrm{g} \cdot \mathrm{mL}^{-1}$ fluoresceine isothiocyanate (FITC)-conjugated $\mathrm{F}\left(\mathrm{ab}^{\prime}\right)_{2}$ fragments of sheep anti-mouse IgG (SAM-FITC; Sigma) in the same medium. AM incubated with isotypic Ig and thereafter with SAM-FITC represented negative controls. After three washings, AM were fixed in $2 \% \mathrm{v} / \mathrm{v}$ formaldehyde in PBS-3\% FBS for 15 min at room temperature, gently scraped with a rubber policeman and kept in the dark at $4{ }^{\circ} \mathrm{C}$ until flow cytometric analysis performed on a FACscan (Becton Dickinson, Mountainview, CA, USA). An additional staining for CD14 was performed on AM preincubated for $24 \mathrm{~h}$ with cytokine by direct immunofluorescence using FITC-conjugated anti-CD14 mAb (clone MøP9, mIgG2b; Becton Dickinson). 
For confocal microscopy, AM $\left(0.2 \times 10^{6} \cdot\right.$ coverslip $\left.^{-1}\right)$ were cultured for $2 \mathrm{~h}$ in 24-well plates, washed with cRPMI, and immunostained for IL-9R as for flow cytometric analysis with AH9R2 mAb. After washings with PBS-3 $\%$ FBS and fixation by $2 \%$ formaldehyde in the same buffer, cells were mounted on slides with 2.5\%,4-diacylbicyclo 2,2,2-octane (Sigma) in Mowiol (Calbiochem-Novabiochem, Darmstadt, Germany), and analysed by a MRC-1024 confocal microscope (Bio Rad Laboratories, Richmond, CA, USA) using a $63 \times$ objective under oil immersion. Images were digitally recorded and reproduced with a photoprinter. Both for flow cytometry and confocal microscopy, IL-9R negative and positive control cells consisted respectively in wild-type and hIL-9Rtransfected Baf-3 cells.

\section{Statistical analysis}

Data were obtained from experiments performed in triplicate and repeated at least three times, and results are expressed as means \pm SEM. As indicated, some results were obtained from experiments performed in duplicate or repeated only twice, and then expressed as means \pm SD. The differences observed between the different groups were analysed by a t-test and Bonferroni's correction was applied when multiple comparisons were performed with a same control condition. A $p<0.05$ was considered to be significant.

\section{Results}

\section{IL-9 and IL-4 inhibit the oxidative burst in} LPS-stimulated AM

Stimulation by LPS for $20 \mathrm{~h}$ increased DCFH oxidation approximately two-fold as compared with unstimulated AM (fig. 1). Although IL-9 did not significantly modulate the oxidative burst in unstimulated AM (data not shown), preincubation for $24 \mathrm{~h}$ with IL-9 downregulated the intracellular oxidative burst in LPS-stimulated AM (6.5 \pm 0.5 versus $10.4 \pm$ $0.3 \mathrm{nmol} \mathrm{DCF} \cdot \mathrm{mg}$ protein $^{-1}, \mathrm{p}<0.001$ ) (fig.1) to its baseline level. A similar inhibitory effect was observed with IL-4 $(6.1 \pm 0.3$ versus $10.4 \pm 0.3 \mathrm{nmol} \mathrm{DCF} \cdot \mathrm{mg}$ protein $^{-1}, \mathrm{p}<0.001$ ) (fig.1). In contrast, preincubation of AM with IFN- $\gamma$ slightly increased the oxidative burst in response to LPS although this effect was not statistically significant (fig. 1).

\section{IL-9-mediated inhibition of the oxidative burst in AM is dose- and time-dependent}

AM were preincubated with various concentrations of IL-9 and were evaluated after LPS stimulation for the intracellular oxidative burst. A dose/response curve was observed considering the inhibition by IL-9 of the respiratory burst in LPS-stimulated AM (fig. 2). In addition, a preincubation period of $24 \mathrm{~h}$ before LPS stimulation was required to observe the inhibitory effect of IL-9 on AM oxidative burst. Thus, no

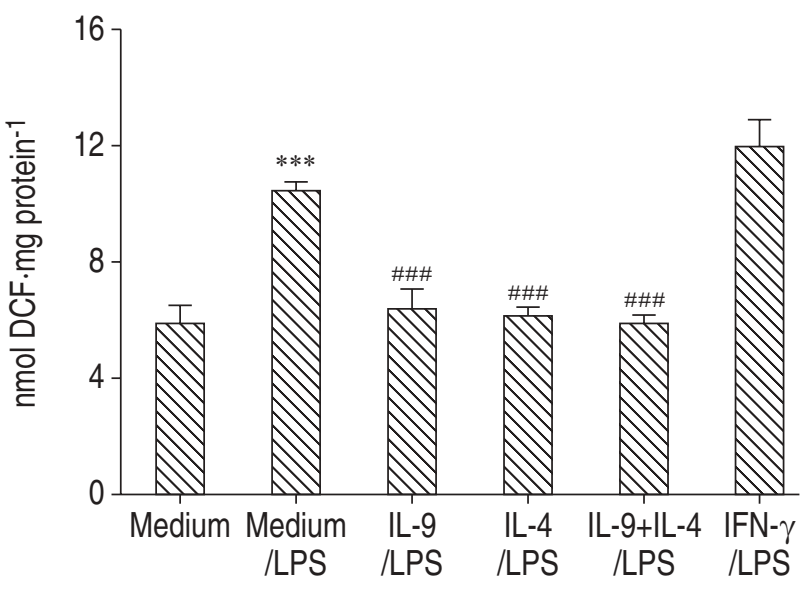

Fig. 1. - Effect of interleukin (IL)-9, IL-4 and interferon (IFN)- $\gamma$ on intracellular oxidative burst in lipopolysaccharide (LPS)stimulated alveolar macrophages (AM). Data are presented as mean \pm SEM obtained from three experiments, performed in triplicate. DCF: dichlorofluorescein. ***: $\mathrm{p}<0.001$ compared with

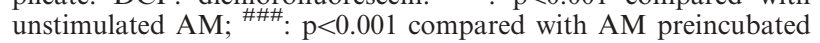
with medium alone and stimulated by LPS.

significant inhibition occurred when AM were preincubated with IL-9 for 4 or $8 \mathrm{~h}$, and no additional inhibition was observed for preincubation periods $>24$ h (data not shown).

$I F N-\gamma$ abrogates the $I L-4$, but not the $I L-9$, inhibitory effect on the oxidative burst in LPS-stimulated AM

The influence of IFN- $\gamma$ on the inhibition mediated by IL-9 and IL- 4 on the oxidative burst in LPSstimulated AM was evaluated by co-incubating cells with IL-9 or IL-4 and IFN- $\gamma$. Inhibition of the respiratory burst by IL-9 in LPS-stimulated AM was maintained in the presence of IFN- $\gamma(6.6 \pm 0.1$ versus $6.5 \pm 0.5 \mathrm{nmol} \mathrm{DCF} \cdot \mathrm{mg}$ protein $^{-1}$, Ns) (fig. 3). In contrast, IFN- $\gamma$ completely abrogated the inhibitory

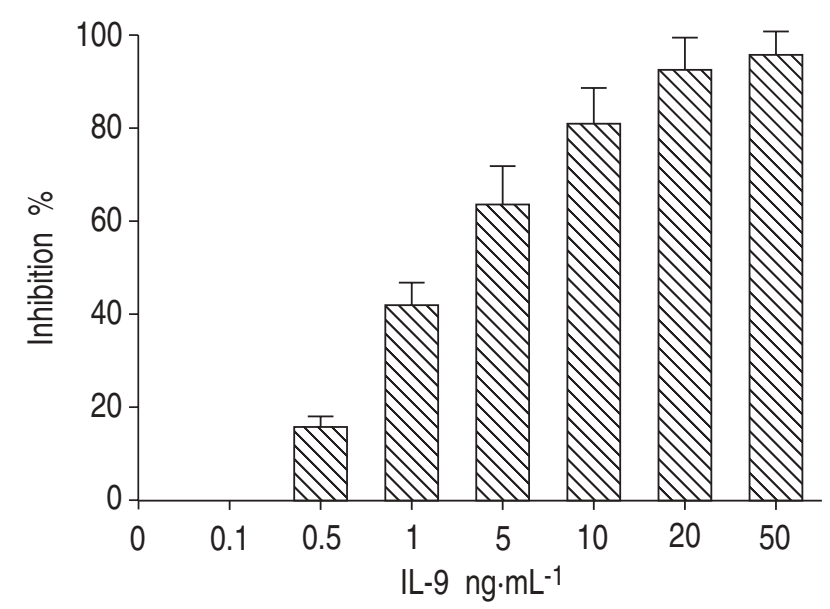

Fig. 2. - Dose effect for the inhibition induced by interleukin (IL)-9 on the oxidative burst in lipopolysaccharide-stimulated alveolar macrophages. Data are presented as means \pm SD $(n=3)$. 


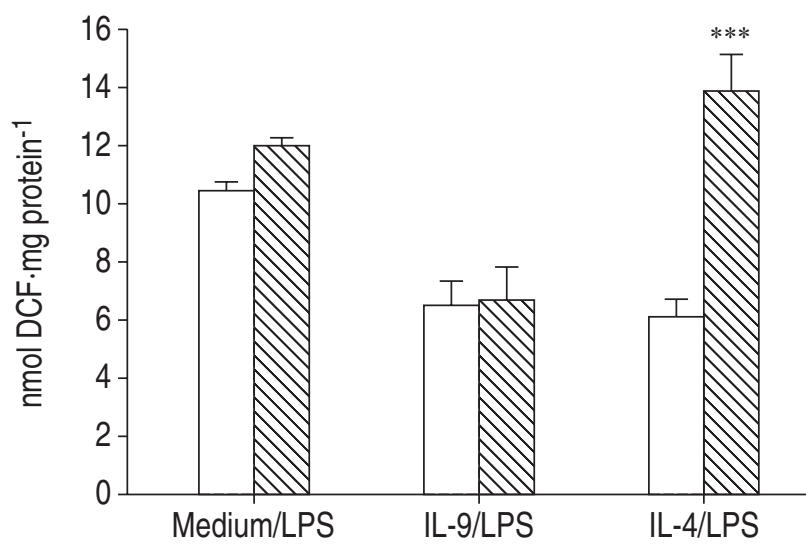

Fig. 3. - Effect of interferon- $\gamma(\mathbb{\mathbb { N }})$ on the inhibition mediated by interleukin (IL)- 9 and IL-4 on the oxidative burst in lipopolysaccharide (LPS)-stimulated alveolar macrophages (AM) ( $\square$ ). ***: $\mathrm{p}<0.001$ compared with AM preincubated with IL-4 alone.

effect of IL-4 on the oxidative burst in LPS-stimulated AM (13.8 \pm 1.3 versus $6.1 \pm 0.3 \mathrm{nmol} \mathrm{DCF} \cdot \mathrm{mg}$ protein $^{-1}$, $\mathrm{p}<0.001$ ) (fig. 3).

\section{IL-9 inhibitory effect on the oxidative burst in $L P S$-stimulated AM is specifically blocked by neutralising anti-IL-9R $\alpha A b$}

In order to confirm the specificity of the observed effect of IL-9 on the AM respiratory burst, AM were pretreated with neutralising anti-hIL-9R $\alpha \mathrm{mAb}$ (AH9R7) before IL-9 incubation. Pretreatment of AM with AH9R $7\left(10 \mu \mathrm{g} \cdot \mathrm{mL}^{-1}\right) 1 \mathrm{~h}$ before addition of IL-9 abolished $90 \pm 5 \%$ (mean \pm SEM) of the IL-9 effect on LPS-stimulated DCFH oxidation. In contrast, no significant change was observed on the IL-9-mediated inhibitory effect with $\mathrm{mIgG} 2 \mathrm{~b}$ used as isotypic control

Table 1. - Specific blockade of the interleukin (IL)-9 inhibitory effect on oxidative burst in lipopolysaccharide (LPS)stimulated alveolar macrophages (AM) by anti-human IL-9 receptor- $\alpha$ (anti-hIL-9R $\alpha$ ) monoclonal antibody (mAb)

\begin{tabular}{lcc}
\hline AM treatment & $\begin{array}{c}\text { Oxidative burst } \\
\text { nmol DCF.mg } \\
\text { protein }^{-1}\end{array}$ & $\begin{array}{c}\text { Blockade of } \\
\text { the IL-9 } \\
\text { effect } \%\end{array}$ \\
\hline Medium & $5.8 \pm 0.6$ & \\
LPS & $10.4 \pm 0.3$ & \\
IL-9/LPS & $6.5 \pm 0.5$ & 0 \\
IL-9+mIgG2b/LPS & $6.2 \pm 0.4$ & $87 \pm 3$ \\
IL-9+anti-IL-9R/LPS & $9.9 \pm 0.3^{* * *}$ & \\
\hline
\end{tabular}

AM $\left(0.2 \times 10^{6}\right)$ were preincubated with neutralising $\mathrm{mAb}$ against anti-hIL-9R $\alpha$ (AH9R7, $\left.10 \mu \mathrm{g} \cdot \mathrm{mL}^{-1}\right)$, or with control blocking mAb against hIL-9R (mIgG2b, $\left.10 \mu \mathrm{g} \cdot \mathrm{mL}^{-1}\right), 1 \mathrm{~h}$ before incubation with IL-9 $\left(20 \mathrm{ng} \cdot \mathrm{mL}^{-1}\right)$ for $24 \mathrm{~h}$, and stimulated by $1 \mu \mathrm{g} \cdot \mathrm{L}^{-1}$ LPS for $20 \mathrm{~h}$. Intracellular oxidative capacity was evaluated by the $2^{\prime}, 7^{\prime}$-dichlorofluorescein (DCF)-diacetate oxidation assay. Data are presented as mean \pm SEM obtained from three experiments performed in triplicate. ${ }^{* *}: \mathrm{p}<0.001$ compared with AM preincubated with IL-9.
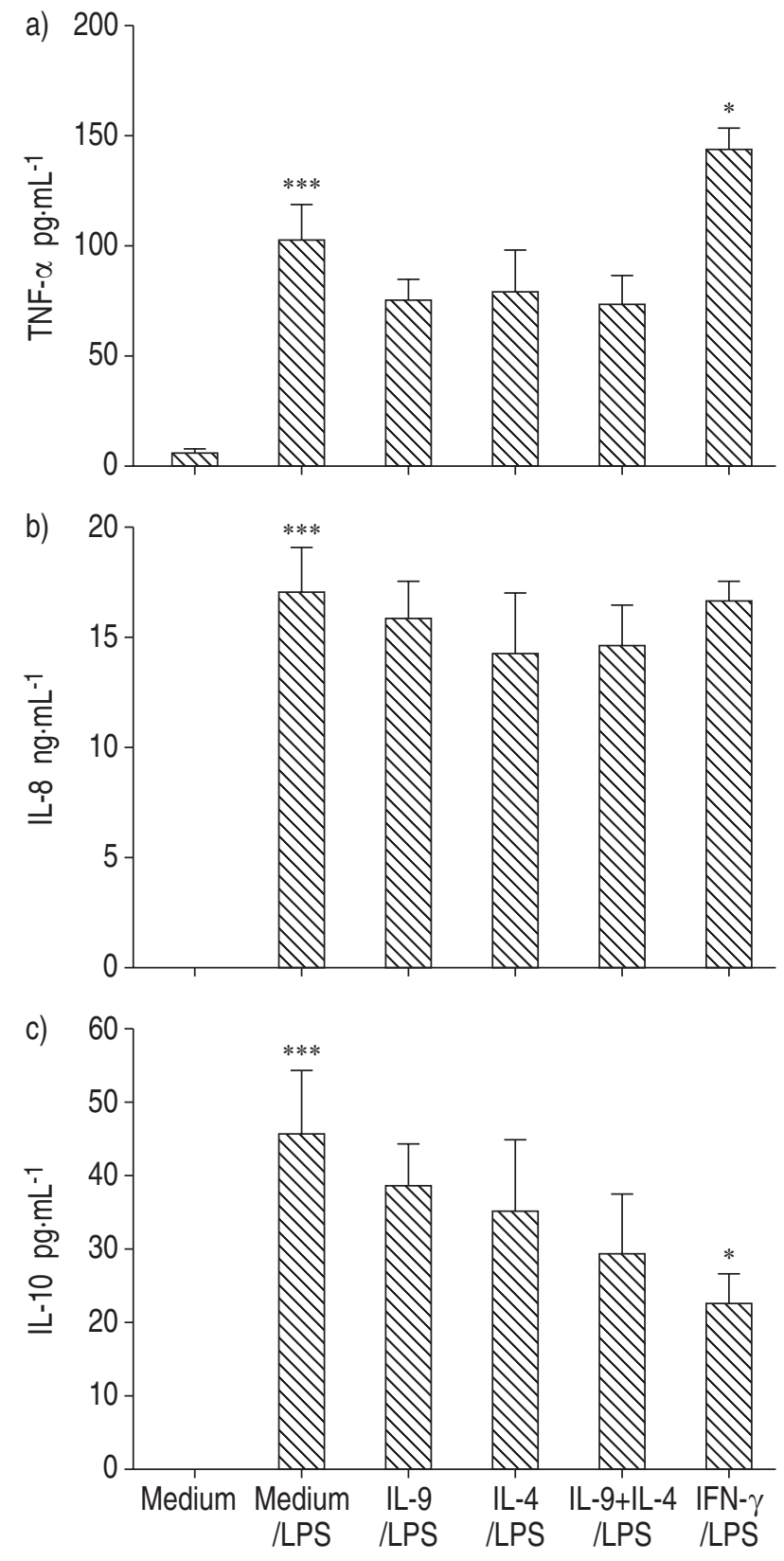

Fig. 4. - Effect of interleukin (IL)-9, IL-4 and interferon (IFN)- $\gamma$ on the release of a) tumour necrosis factor (TNF)- $\alpha$, b) IL-8 and c) IL-10 by lipopolysaccharide (LPS)-stimulated alveolar macrophages (AM). Data are mean \pm SEM $(n=3)$. *: $p<0.05$ compared with AM preincubated with medium alone and stimulated by LPS; ***: $\mathrm{p}<0.001$ compared with unstimulated AM.

(table 1), nor on the IL-4-mediated inhibition with anti-hIL-9R $\alpha$ mAb (data not shown).

$I L-9$ and $I L-4$ fail to regulate the production of $T N F-\alpha$, IL-8 and IL-10 by LPS-stimulated AM

Constitutively, AM released very low levels of TNF- $\alpha$ and no detectable amounts of IL- 8 and IL-10 (fig. 4). As expected, stimulation of AM by LPS for $20 \mathrm{~h}$ strongly induced the secretion of these 
cytokines. In LPS-stimulated AM, the preincubation with IL-9 or IL-4 slightly reduced the TNF- $\alpha$ production, but without reaching statistical significance (74.8 \pm 10.2 and $80.3 \pm 19.7$, respectively, versus $102.4 \pm$ $17.6 \mathrm{pg} \cdot \mathrm{mL}^{-1}$, Ns) (fig. 4). In contrast, IFN- $\gamma$ slightly potentiated the TNF- $\alpha$ release by LPS-stimulated AM ( $145 \pm 9.4$ versus $102.4 \pm 17.6 \mathrm{pg} \cdot \mathrm{mL}^{-1}, \mathrm{p}<0.05$ ) (fig. 4). Similar to TNF- $\alpha$, no significant modulation of the IL-8 release was observed in AM pretreated with IL-9, nor with IL-4 (fig. 4). The LPS-induced IL-10 production was clearly inhibited by IFN- $\gamma(22.5 \pm 4$ versus $\left.45.3 \pm 9.2 \mathrm{pg} \cdot \mathrm{mL}^{-1}, \mathrm{p}<0.001\right)$, and also slightly reduced by IL-9 and IL-4 but without reaching statistical significance $\left(38.4 \pm 5.7\right.$ and $35.1 \pm 9.8 \mathrm{pg} \cdot \mathrm{mL}^{-1}$, respectively, versus $45.3 \pm 9.2 \mathrm{pg} \cdot \mathrm{mL}^{-1}$, Ns) (fig. 4).

\section{IL-4 but not IL-9 inhibits surface expression of CD14 $L P S$ receptor on $A M$}

CD14 was detected at the surface of AM, although to a much less extent than on blood monocytes [7]. CD14 expression at the surface of AM was downregulated by preincubation with IL-4 (mean fluorescence intensity (MFI) $42 \pm 4$ versus $84 \pm 6, \mathrm{p}<0.001$ ). Conversely, IFN- $\gamma$ increased CD14 on AM, although this effect was below the level of statistical significance (MFI $111 \pm 5$ versus $84 \pm 6$, Ns) (table 2 ). In contrast, IL-9 did not change the expression level of surface CD14 on AM (table 2).

\section{IL-9 strongly potentiates the production of TGF- $\beta 1$ by $A M$}

A slight increase of TGF- $\beta 1$ was observed in supernatants from unstimulated AM incubated with IL-9 (68 \pm 9 versus $39 \pm 8 \mathrm{pg} \cdot \mathrm{mL}^{-1}$ in acid-treated supernatants, $\mathrm{p}<0.05)$. More importantly, the production of TGF- $\beta 1$ by LPS-activated AM was strongly potentiated by IL-9 $\left(366 \pm 21\right.$ versus $109 \pm 23 \mathrm{pg} \cdot \mathrm{mL}^{-1}$ in acidtreated supernatants, $\mathrm{p}<0.001$ ) (fig. 5). This effect was not observed with IL-4 nor with IFN- $\gamma$. Moreover, the IL-9-mediated TGF- $\beta 1$ upregulation was specifically

Table 2.-Cytokine-mediated modulation of CD14 expression on alveolar macrophages (AM)

AM treatment

CD14 expression (MFI)

\begin{tabular}{lc}
\hline Medium & $84 \pm 6$ \\
IL-9 & $88 \pm 7$ \\
IL-4 & $42 \pm 4^{*}$ \\
IFN- $\gamma$ & $111 \pm 5^{*}$ \\
\hline
\end{tabular}

AM $\left(0.2 \times 10^{6}\right)$ were preincubated for $24 \mathrm{~h}$ with cytokines $\left(20 \mathrm{ng} \cdot \mathrm{mL}^{-1}\right.$ for interleukin (IL)-9 or IL-4 and $200 \mathrm{U} \cdot \mathrm{mL}$ for interferon (IFN)- $\gamma$ ), before the assessment of CD14 expression by direct immunostaining using anti-human CD14 monoclonal antibodies conjugated to fluorescein isothiocyanate. Cell-associated fluorescence was evaluated by flow cytometry and expressed as mean fluorescence intensity (MFI). Autofluorescence of AM was negligible (MFI $3 \pm 1$ ). Data are presented as means \pm SD $(n=3)$, and are representative of two experiments. *: $\mathrm{p}<0.05$ compared with AM preincubated with medium alone.

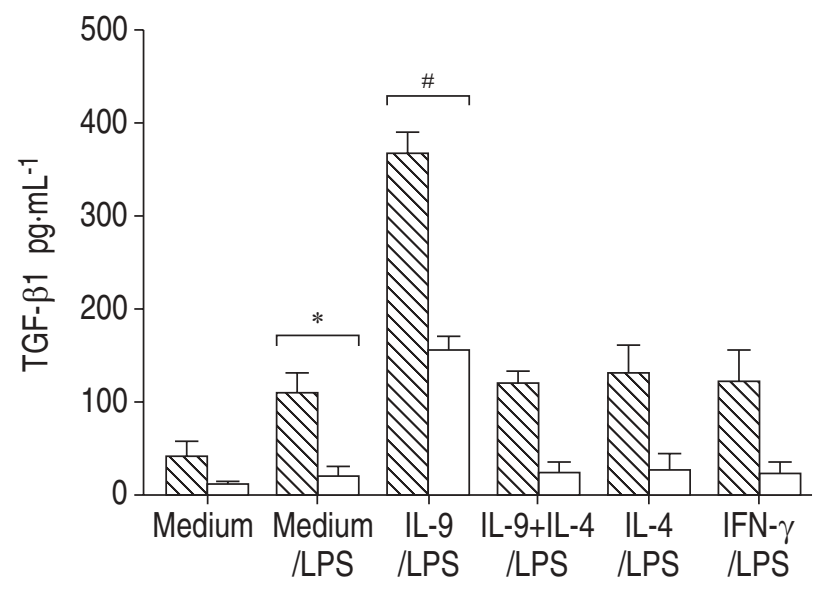

Fig. 5.-Effect of interleukin (IL)-9, IL-4 and interferon (IFN)- $\gamma$ on the release of tumour growth factor (TGF)- $\beta$ by lipopolysaccharide (LPS)-stimulated alveolar macrophages (AM). TGF- $\beta$ was determined by in untreated $(\square)$ and in acid-treated $(\mathbb{Q})$ supernatants. Data are presented as mean \pm SEM $(n=3)$. *: $\mathrm{p}<0.05$ compared with unstimulated AM; ${ }^{\#}:$ p $<0.05$ compared with AM preincubated with medium.

inhibited by neutralising anti-IL-9R $\alpha \mathrm{mAb}(118 \pm 14$ versus $366 \pm 21 \mathrm{pg} \cdot \mathrm{mL}^{-1}, \mathrm{p}<0.001$ ) (fig. 5), and not by control mIgG2b.

\section{Inhibition by IL-9 of the oxidative burst in LPS-activated AM depends on TGF- $\beta 1$}

Considering that TGF- $\beta$ has been previously identified as a major macrophage deactivating factor and that its secretion was stimulated by IL-9, the possibility that TGF- $\beta$ might mediate the inhibitory effect of IL-9 on the oxidative burst in AM was addressed. Interestingly, similarly to blood monocytes [7], the IL-9-induced inhibition of the respiratory

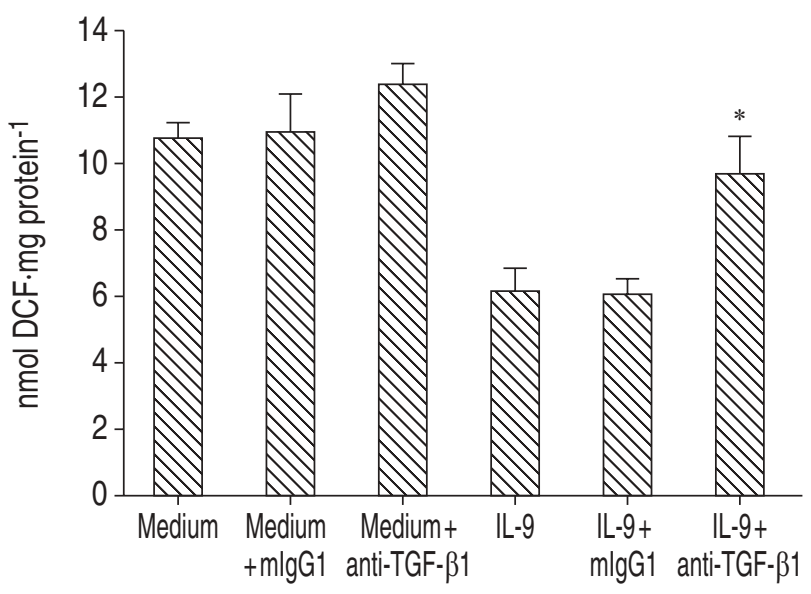

Fig. 6.-Effect of anti-tumour growth factor (TGF)- $\beta 1$ monoclonal antibody (mAb) on the interleukin (IL)-9-induced inhibition of the oxidative burst in lipopolysaccharide (LPS)-stimulated alveolar macrophages (AM). AM were pretreated with anti-TGF- $\beta 1$ $\mathrm{mAb}$ or with control mouse immunoglobulin (mIg)G1, 2 h before the preincubation for $24 \mathrm{~h}$ with IL-9 or medium alone. Data are presented as mean $\pm S D(n=3)$, and are representative of two experiments. DCF: dichlorofluorescein. 

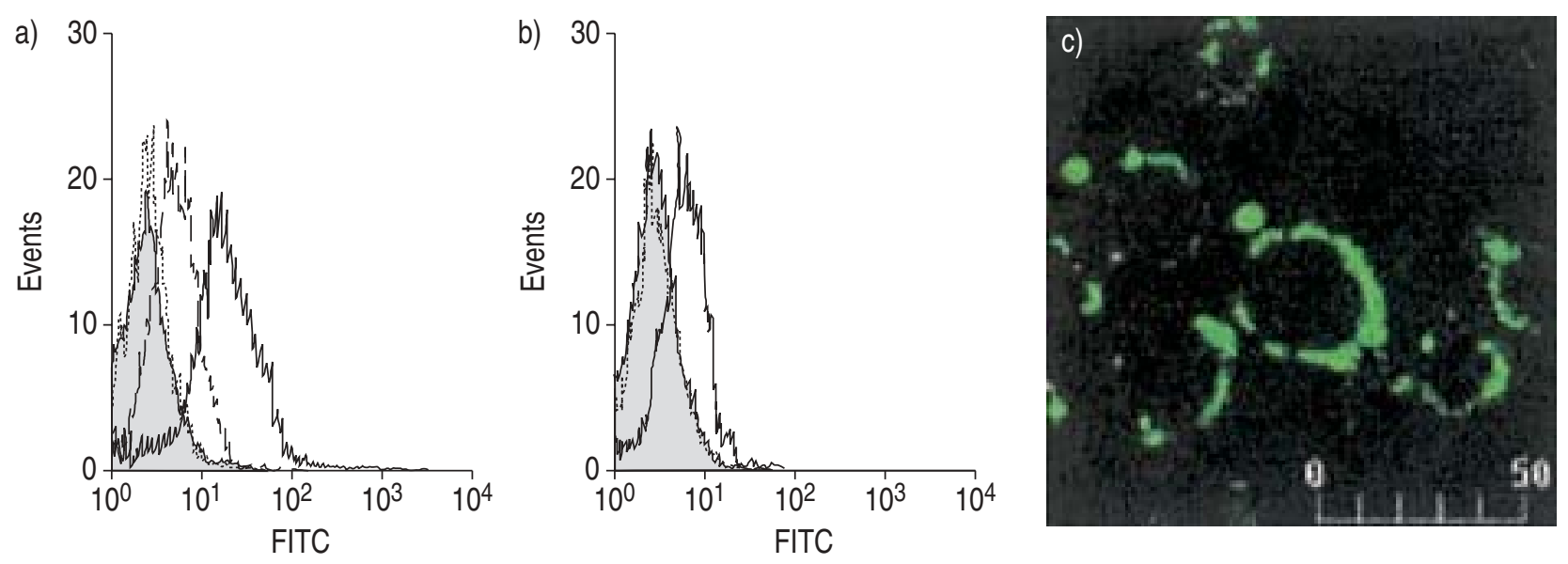

Fig. 7. - Flow cytometric analysis of a) interleukin (IL)-9 receptor (R) $\alpha$ and b) IL-2R $\gamma$ chain expression by alveolar macrophages (AM). AM were incubated with AH9R2 (-) or AH9R7 (---) monoclonal antibodies (mAb) or with anti-human (h) IL-2R $\gamma$, and thereafter with fluoresceine isothiocyanate (FITC)-conjugated sheep anti-mouse immunoglobulin antibody. Autofluorescence (shaded histogram) and control $(\cdots \cdots)$ histograms are also shown. The figure is representative of five experiments. c) IL-9R $\alpha$ staining of AM with AH9R2 mAb was also evaluated by confocal microscopy (inset, scale $=\mu \mathrm{m}$ ).

burst in LPS-stimulated AM was abrogated by the blockade of TGF- $\beta 1$ activity by a specific $\mathrm{mAb}$, and not by control mIgG1 (fig. 6). This abrogation by anti-TGF- $\beta 1 \mathrm{mAb}$ was not observed on the inhibition induced by IL-4 (data not shown).

\section{AM express specific receptors for $I L-9$}

Specific surface receptors for IL-9 were identified on AM. The presence of IL-9R $\alpha$ chain was thus demonstrated on AM by flow cytometry and confocal microscopy, after immunostaining using different specific mAbs (AH9R2 and AH9R7) (fig. 7). Positive control cells (hIL-9R $\alpha$-transfected Baf-3 cells) exhibited a similar pattern of surface fluorescence, whereas no shift of the fluorescence histogram was observed in wild-type Baf-3 control cells (data not shown). The level of expression of IL-9R $\alpha$ was not significantly changed by IL-9, IL-4 or IFN- $\gamma$ on AM cultured for $24 \mathrm{~h}$ with these cytokines (data not shown). The other subunit of the IL-9R complex, IL-2R $\gamma(\gamma \mathrm{c})$, was also identified on AM (fig. 7), although the expression level of this latter receptor appeared quite variable among the different volunteers (data not shown).

\section{Discussion}

The authors have previously shown that IL-9, a Th2 cytokine [15], inhibits the production of reactive oxygen intermediates (ROI) and TNF- $\alpha$ by human blood monocytes [7]. It is shown here that IL-9 can also regulate some important functions of human AM. Thus, pretreatment of AM with IL-9 inhibited their subsequent production of ROI after LPS stimulation. In contrast, the LPS-stimulated cytokine release by AM was not significantly affected by IL-9 nor by IL-4. Interestingly, in contrast with IL-4, which exhibited a similar deactivating activity on AM respiratory burst, IL-9 stimulated the production of
TGF- $\beta 1$ by AM. Moreover, TGF- $\beta 1$ was required for the inhibitory effect of IL-9 on AM oxidative burst to be seen.

In contrast with IFN- $\gamma$, which represents a major priming factor for AM respiratory burst [16] and cytokine release [17], Th2 cytokines (such as IL-4, IL-10 and IL-13) and TGF- $\beta$ have generally been described as macrophage-deactivating factors. In particular, BHASKARAN et al. [18] showed that IL-4 deactivates AM for the oxidative burst response to LPS. Correspondingly, in this study it has been shown that IL-9 inhibits the production of ROI in AM stimulated by LPS. While ROI are probably required to clear the lung from intracellular pathogens [19], the role of these toxic metabolites has also been demonstrated in lung tissue injury in vivo [20]. Thus, the inhibition of $\mathrm{H}_{2} \mathrm{O}_{2}$ generation in activated $\mathrm{AM}$ by IL-4 and IL-9 might have an important role in the prevention of tissue injury during some inflammatory processes occurring in the alveoli. In this regard, it is of interest that the inhibitory effects mediated by IL-4 and IL-9, which could appear as redundant, are differently modulated by IFN- $\gamma$, probably produced concomitantly during immune responses in the lung. Thus, the inhibition of the oxidative burst in LPSactivated AM by IL- 4 is antagonised by IFN- $\gamma$ as previously shown [21], in contrast to that of IL-9.

In contrast with the regulation of AM oxidative burst, IL-4 and IL-9 did not change the release of several cytokines by AM. Thus, both IL-4 and IL-9 failed to significantly modulate the release of TNF- $\alpha$, IL- 8 and IL-10 by LPS-stimulated AM, although there was a tendency to inhibition especially for IL-10 production. Several studies have reported that IL-4 inhibits the release of inflammatory mediators by activated AM, namely TNF- $\alpha$ and IL-1 $\beta$ [22-24], IL-6 [25], monocyte chemotactic peptide-1 [10], IL-12 [26] or prostaglandin $\mathrm{E}_{2}[27,28]$. However, other studies failed to demonstrate a significant effect of IL-4 on cytokine production in AM [29], as well as in synovial macrophages or in monocyte-derived macrophages 
[9]. One possible explanation for the relative loss of IL-9 and IL-4 activity on tissue macrophages, as compared to blood monocytes, was a reduced expression of the IL-2R $\gamma$ chain, the common subunit notably shared by receptors for IL-4 and IL-9 [30]. However, the present data show that both IL-4 and IL-9 can regulate AM, notably for the oxidative metabolism, and that IL-2R $\gamma$ is expressed by these tissue macrophages.

The production of TGF- $\beta$ by activated AM is strongly potentiated by IL-9, but not by IL-4. Interestingly, using antibodies to neutralise TGF- $\beta 1$, it was shown that the upregulation by IL-9 of the TGF- $\beta$ pathway is required for the IL-9-mediated inhibition of AM oxidative burst to be seen. This is in agreement with previous studies indicating that TGF- $\beta$ is a major macrophage deactivating factor, notably for the production of ROI [31]. In addition, this observation could explain, at least in part, the need for a preincubation period for IL-9 to inhibit the oxidative burst in LPS-activated AM. Conversely, TGF- $\beta$, which is produced as a latent procytokine complex, has been identified as a major fibrosing agent $[32,33]$. Although a Th2 inflammatory profile was associated with fibrotic lung diseases such as idiopathic pulmonary fibrosis [34] or bleomycininduced lung fibrosis [35], this relationship between Th2 inflammation and tissue fibrosis remains poorly understood. LEE et al. [36] recently showed that IL-13 induces lung fibrosis through the activation of TGF- $\beta$, suggesting that TGF- $\beta$ might represent a link between Th2 inflammation and lung fibrosis. The present data, showing that TGF- $\beta$ upregulation can be induced by IL-9 in activated AM, supports this concept. Conversely, Arras et al. [6] reported that IL-9 inhibits rather than potentiates lung fibrosis in a mouse model of silicosis, and this effect was associated with an inhibition of the silica-induced Th2 polarisation. Thus, other mechanisms could occur in vivo with regard to the cytokine network or to alternative regulatory pathways. More specifically, it has been shown that $\mathrm{H}_{2} \mathrm{O}_{2}$ can induce connective tissue growth factor (CTGF) [37] which mediates the effect of TGF- $\beta$ on fibroblast collagen synthesis [38]. Therefore, IL-9 might induce a profibrotic activity in the lung through increased TGF- $\beta$ secretion by activated AM, while the downregulation of the oxidative burst might prevent tissue fibrosis by limiting the induction of CTGF.

The modulation of surface expression of CD14 on AM represents a potential regulatory mechanism of cell activation, since this receptor is required to induce the signalling events leading to the synthesis of inflammatory cytokines elicited by LPS [39]. The current authors have confirmed that CD14 expression on AM is downregulated by IL-4, as previously shown $[27,40]$. This is in contrast with IL-9, which had no effect on CD14 expression in AM. In addition, the authors observed that IFN- $\gamma$ can neutralise the reduction of CD14 on AM induced by IL-4 (data not shown). These effects might represent mechanisms of deactivation or priming of AM by IL- 4 and IFN- $\gamma$, respectively, with regard to further LPS stimulation.

In conclusion, the authors report that interleukin-9 inhibits the production of reactive oxygen species in activated alveolar macrophages, similarly to interleukin-4. In contrast with the release of tumour necrosis factor- $\alpha$, interleukin- 8 and -10 , which is not significantly affected by interleukin- 9 or -4 , the production of tumour growth factor- $\beta 1$ by activated alveolar macrophages is strongly enhanced by interleukin-9 and this tumour growth factor- $\beta 1$ upregulation mediates the inhibitory effect of interleukin-9 on the oxidative burst. Finally, the modulation of CD14 expression which appears as a potential mechanism of alveolar macrophage deactivation by interleukin-4, as well as of priming by interferon- $\gamma$, is not observed with interleukin-9. These observations highlight regulatory pathways of alveolar macrophage activation by T-helper 2 cytokines and provide new information on interleukin-9 relating to alveolar macrophage biology.

\footnotetext{
Acknowledgements. The authors would like to thank P. Courtoy (Cell Unit, Institute of Cellular Pathology, Université de Louvain, Brussels) for access to the confocal microscope.
}

\section{References}

1. Renauld JC. New insights into the role of cytokines in asthma. J Clin Pathol 2001; 54: 577-589.

2. Dugas B, Renauld JC, Pene J, et al. Interleukin-9 potentiates the interleukin-4-induced immunoglobulin ( $\mathrm{IgG}, \mathrm{IgM}$ and $\mathrm{IgE}$ ) production by normal human B lymphocytes. Eur J Immunol 1993; 23: 1687-1692.

3. Hultner L, Druez C, Moeller J, et al. Mast cell growthenhancing activity (MEA) is structurally related and functionally identical to the novel mouse $\mathrm{T}$ cell growth factor P40/TCGFIII (interleukin 9). Eur J Immunol 1990; 20: 1413-1416.

4. Louahed J, Zhou Y, Maloy WL, et al. Interleukin 9 promotes influx and local maturation of eosinophils. Blood 2001; 97: 1035-1042.

5. Louahed J, Toda M, Jen J, et al. Interleukin-9 upregulates mucus expression in the airways. $A m$ J Respir Cell Mol Biol 2000; 22: 649-656.

6. Arras M, Huaux F, Vinck A, et al. Interleukin-9 reduces lung fibrosis and type 2 immune polarization induced by silica particles in a murine model. Am J Respir Cell Mol Biol 2001; 24: 368-375.

7. Pilette C, Ouadrhiri Y, Van Snick J, Renauld JC, Vaerman JP, Sibille Y. Interleukin-9 inhibits oxidative burst in LPS-stimulated human blood monocytes through TGF- $\beta$. J Immunol 2002; 168: 4103-4111.

8. Grohmann U, Van Snick J, Campanile F, et al. IL-9 protects mice from Gram-negative bacterial shock: suppression of TNF-alpha, IL-12, and IFN-gamma, and induction of IL-10. J Immunol 2000; 164: 41974203.

9. Bonder CS, Finlay-Jones JJ, Hart PH. Interleukin-4 regulation of human monocyte and macrophage interleukin-10 and interleukin-12 production. Role of a functional interleukin-2 receptor $\gamma$-chain. Immunol 1999; 96: 529-536.

10. Yano S, Yanagawa H, Nishioka Y, Mukaida N, Matsushima K, Sone S. T helper 2 cytokines differently regulate monocyte chemoattractant protein-1 production by human peripheral blood monocytes 
and alveolar macrophages. J Immunol 1996; 157 : 2660-2665.

11. Sibille Y, Reynolds HY. Macrophages and polymorphonuclear neutrophils in lung defence and injury. Am Rev Respir Dis 1990; 141: 471-501.

12. Sibille Y, Chatelin B, Staquet P, Merrill WW, Delacroix DL, Vaerman JP. Surface IgA and Fc alpha-receptors on human alveolar macrophages from normal subjects and from patients with sarcoidosis. Am Rev Respir Dis 1989; 139: 740-747.

13. Bass DA, Parce JW, DeChatelet LR, Szeda P, Seeds MC, Thomas M. Flow cytometric studies of oxidative product formation by neutrophils: a graded response to membrane stimulation. J Immunol 1983; 130: $1910-1917$.

14. Espevik T, Nissen-Meyer J. A highly sensitive cell line, WEHI 64 clone 13, for measuring cytotoxic factor/tumor necrosis factor from human monocytes. J Immunol Methods 1986; 95: 99-105.

15. Uyttenhove C, Simpson RJ, Van Snick J. Functional and structural characterization of $\mathrm{P} 40$, a mouse glycoprotein with T-cell growth factor activity. Proc Natl Acad Sci USA 1998; 85: 6934-6938.

16. Meyer KC, Powers C, Cornwell R, Borden EC. Priming of human alveolar macrophages and blood monocytes for superoxide anion release by interferons and lipopolysaccharide. J Interferon Res 1991; 11: 283-290.

17. Déry RE, Bissonnette EY. IFN- $\gamma$ potentiates the release of TNF- $\alpha$ and MIP- $1 \alpha$ by alveolar macrophages during allergic reactions. Am J Respir Cell Molec Biol 1999; 20: 407-412.

18. Bhaskaran G, Nii A, Sone S, Ogura T. Differential effects of interleukin-4 on superoxide anion production by human alveolar macrophages stimulated with lipopolysaccharide and interferon-gamma. J Leukoc Biol 1992; 52: 218-223.

19. Blauer F, Groscurth P, Schneemann M, Schoedon G, Schaffner A. Modulation of the antilisterial activity of human blood-derived macrophages by activating and deactivating cytokines. J Interferon Cytokine Res 1995; 15: 105-114.

20. Johnson KJ, Ward PA. Role of oxygen metabolites in immune complex injury of lung. J Immunol 1981; 126: 2365-2369.

21. Becker S, Daniel EG. Antagonistic and additive effects of IL-4 and interferon- $\gamma$ on human monocytes and macrophages: effects on $\mathrm{Fc}$ receptors, HLA-D antigens, and superoxide production. Cell Immunol 1990; 129: 351-362.

22. Nishioka Y, Sone S, Orino E, Nii A, Ogura T. Downregulation by interleukin 4 of activation of human alveolar macrophages to the tumoricidal state. Cancer Res 1991; 51: 5526-5531.

23. Sone S, Yanagawa H, Nishioka Y, et al. Interleukin-4 as a potent down-regulator of human alveolar macrophages capable of producing tumour necrosis factor-alpha and interleukin-1. Eur Respir J 1992; 5: 174-181.

24. Chanez $\mathrm{P}$, Vignola $\mathrm{AM}$, Paul-Eugene $\mathrm{N}$, et al. Modulation by interleukin-4 of cytokine release from mononuclear phagocytes in asthma. $J$ Allergy Clin Immunol 1994; 94: 997-1005.

25. Yanagawa H, Sone S, Sugihara K, Tanaka K, Ogura T. Interleukin-4 downregulates interleukin-6 production by human alveolar macrophages at protein and mRNA levels. Microbiol Immunol 1991; 35: 879-893.

26. Dobashi K, Aihara M, Araki T, et al. Regulation of LPS induced IL-12 production by IFN-gamma and IL-4 through intracellular glutathione status in human alveolar macrophages. Clin Exp Immunol 2001; 124 : 290-296.

27. Yano T, Hopkins HA, Hempel SL, Monick M, Hunninghake GW. Interleukin-4 inhibits lipopolysaccharide-induced expression of prostaglandin $\mathrm{H}$ synthase-2 in human alveolar macrophages. $J$ Cell Physiol 1995; 165: 77-82.

28. Endo T, Ogushi F, Kawano T, Sone S. Comparison of the regulations by Th2-type cytokines of the arachidonic-acid metabolic pathway in human alveolar macrophages and monocytes. Am J Respir Cell Mol Biol 1998; 19: 300-307.

29. Yanagawa H, Takeuchi E, Suzuki Y, et al. Production of interleukin-10 by alveolar macrophages from lung cancer patients. Respir Med 1999; 93: 666-667.

30. Hart PH, Bonder CS, Balogh J, Dickensheets HL, Donnelly RP, Finlay-Jones JJ. Differential responses of human monocytes and macrophages to IL-4 and IL-13. J Leukoc Biol 1999; 66: 575-578.

31. Tsunawaki S, Sporn M, Ding A, Nathan C. Deactivation of macrophages by transforming growth factorbeta. Nature 1988; 334: 260-262.

32. Roberts AB, Sporn MB, Assoian RK, et al. Transforming growth factor type beta: rapid induction of fibrosis and angiogenesis in vivo and stimulation of collagen formation in vitro. Proc Natl Acad Sci USA 1986; 83: 4167-4171.

33. Ignotz RA, Endo T, Massague J. Regulation of fibronectin and type I collagen mRNA levels by transforming growth factor-beta. J Biol Chem 1987; 262: 6443-6446.

34. Wallace WA, Ramage EA, Lamb D, Howie SE. A type 2 (Th2-like) pattern of immune response predominates in the pulmonary interstitium of patients with cryptogenic fibrosing alveolitis (CFA). Clin Exp Immunol 1995; 101: 436-441.

35. Gharaee-Kermani M, Phan SH. Lung interleukin-5 expression in murine bleomycin-induced pulmonary fibrosis. Am J Respir Cell Mol Biol 1997; 164: 438-447.

36. Lee CG, Homer RJ, Zhu Z, et al. Interleukin-13 induces tissue fibrosis by selectively stimulating and activating transforming growth factor $\beta 1 . J$ Exp Med 2001; 194: 809-821.

37. Park SK, Kim J, Seomun Y, et al. Hydrogen peroxide is a novel inducer of connective tissue growth factor. Biochem Biophys Res Commun 2001; 284: 966-971.

38. Grotendorst GR. Connective tissue growth factor: a mediator of TGF- $\beta$ action on fibroblasts. Cytokine Growth Factor Rev 1997; 8: 171-179.

39. Martin TR, Mathison JS, Tobias PS, et al. Lipopolysaccharide binding protein enhances the responsiveness of alveolar macrophages to bacterial lipopolysaccharide. Implications for cytokine production in normal and injured lungs. J Clin Invest 1992; 90: 2209-2219.

40. Hasday JD, Dubin W, Mongovin S, et al. Bronchoalveolar macrophage CD14 expression: shift between membrane-associated and soluble pools. Am J Physiol 1997; 272: L925-L933. 